\title{
Long-term effects of gastrectomy in patients with spirometry-defined COPD and patients at risk of COPD: a case-control study
}

This article was published in the following Dove Press journal:

International Journal of COPD

29 October 2015

Number of times this article has been viewed

\author{
Hitoshi Saito ${ }^{1,2}$ \\ Koichiro Nomura ${ }^{1,2, \dagger}$ \\ Shinji Abe ${ }^{1,2}$ \\ Takashi Motegi ${ }^{2,3}$ \\ Takeo Ishii ${ }^{2,3}$ \\ Kumiko Hattori ${ }^{2,3}$ \\ Yuji Kusunoki ${ }^{2,3}$ \\ Akihiko Gemma ${ }^{2}$ \\ Kozui Kida ${ }^{2,3}$ \\ 'Department of Respiratory Medicine, \\ Tokyo Metropolitan Hiroo Hospital, \\ ${ }^{2}$ Department of Pulmonary Medicine \\ and Oncology, Graduate School of \\ Medicine, ${ }^{3}$ Respiratory Care Clinic, \\ Nippon Medical School, Tokyo, Japan \\ †Koichiro Nomura passed away \\ on July 30,2014
}

Correspondence: Kozui Kida Respiratory Care Clinic, Nippon Medical School, 4-7-I5-8F, Kudan-minami, Chiyoda-ku, Tokyo 102-0074, Japan Tel +8 I 352762325

Fax +81352762326

Email kkida@nms.ac.jp
Objective: Comorbidities are characteristic of COPD. However, little is known about the secondary manifestations of COPD in the gastrointestinal tract. Therefore, we aimed to explore the long-term effects of gastrectomy in patients with spirometry-defined COPD or those at risk of COPD.

Participants: Subjects included 87 patients either with COPD or at risk of COPD (symptomatic) who underwent gastrectomy between December 2003 and October 2013 (group A), and 174 patients either with COPD or at risk of COPD, matched by age ( \pm 5 years), sex, and forced expiratory volume in 1 second $\left(\mathrm{FEV}_{1}\right)$ as percentage of predicted $\left(\mathrm{FEV}_{1} \%\right.$ predicted) ( $\pm 5 \%$ ) (group B).

Methods: All patients underwent routine blood chemistry and pulmonary function tests, arterial blood gas analysis, 6-minute walk test (6MWT), high-resolution chest computed tomography scans, and nutritional assessments.

Results: The mean duration postgastrectomy was $18.3 \pm 15.4$ years. The mean $\mathrm{FEV}_{1}$ and $\mathrm{FEV}_{1} \%$ predicted were $2.07 \pm 0.76 \mathrm{~L}$ and $74.6 \pm 24.5 \%$, respectively. Univariate analysis indicated that group A patients had significantly lower body mass index, fat-free mass index, and serum hemoglobin and albumin concentration (all $P=0.00$ ), and walked a significantly shorter distance in the 6MWT $(P<0.05)$. Multivariate linear regression analysis for the distance in the 6MWT indicated that increased residual volume (RV) to total lung capacity (TLC) as percentage of predicted (\%RV/ TLC) alone was an independent and significant predictor of reduced distances in the 6MWT.

Conclusion: We concluded that nutritional insufficiency in patients with COPD (or those at risk of COPD) who previously underwent gastrectomy might lead to hyperinflation and consequently, decreased exercise capacity.

Keywords: chronic obstructive pulmonary disease, nutritional insufficiency, 6-minute walk test

\section{Introduction}

COPD is associated with a high prevalence of comorbid conditions, including lung cancer, cardiovascular diseases, metabolic diseases, and musculoskeletal diseases. ${ }^{1}$ There is a growing clinical interest in the manifestations of COPD in organs other than the lungs, particularly the gastrointestinal tract. For example, Rutten et $\mathrm{al}^{2}$ provided evidence of associated intestinal dysfunctions in patients with COPD. Current information suggests that various endogenous nutritional and functional changes associated with the stomach may be related to COPD. Ghrelin deficiency, for example, is profoundly associated with weight loss; ${ }^{3}$ Nagaya et $\mathrm{al}^{4}$ investigated whether administration of ghrelin improves cachexia and functional capacity in patients with COPD. Their preliminary results suggest that repeated administration of ghrelin reduces muscle wasting and improves 
body composition, functional capacity, and sympathetic augmentation in cachectic patients with COPD.

Bariatric surgical procedures, such as vertical sleeve gastrectomy, are considered effective therapeutic options for the treatment of obesity and are associated with considerable improvements in comorbidities, including type 2 diabetes mellitus. Cummings et al ${ }^{5}$ examined whether weight loss after gastric bypass surgery might be accompanied by impaired ghrelin secretion. Hanusch-Enserer et $\mathrm{al}^{6}$ suggested that gastric banding decreases the plasma ghrelin concentration and leads to body weight changes. There is also some doubt as to the role of leptin versus that of ghrelin. ${ }^{7}$ However, the current understanding is that a high plasma concentration of the peptide $\mathrm{YY}_{3-36}$, a physiological gut-derived satiety signal mimicking the fed state, is observed in patients after gastric bypass or sleeve gastrectomy. ${ }^{8}$ Infusions of normal postprandial concentrations of peptide $\mathrm{YY}_{3-36}$ has been found to significantly decrease appetite and reduces food intake. ${ }^{9}$ Research also suggests an important role for the nuclear farnesoid-X receptor (also known as NR1H4) as a molecular factor underpinning the beneficial effects of this type of weight loss surgery. ${ }^{10}$ However, little is known about the physical and physiological effects of the surgery, such as its effect on lung function tests or routine activity long after gastrectomy.

Historically, a close relationship between peptic ulceration and emphysema has been observed, mainly from clinical observations. Reliable data are limited, as only two studies have examined the relationship between peptic ulcers and the severity of emphysema. ${ }^{11}$ Authors have also suggested that peptic ulcers may be related to some aspect of chronic airflow obstruction. ${ }^{11}$

In view of this finding, we hypothesized that there is a close association between COPD and various gastric diseases and thus, studying postgastrectomy patients with COPD could be advantageous. However, there has been a dramatic decrease in the use of gastrectomy in developed countries in favor of new, more effective treatments. For instance, partial or total gastrectomy was previously the main treatment for peptic ulcers; however, curing Helicobacter pylori infection appears to decrease recurrent ulceration and the severity of the perforation associated with it. ${ }^{12}$ Thus, the number of patients who undergo gastrectomy to treat peptic ulcers or early gastric cancer is likely to decrease rapidly in the near future, making it difficult to test our hypothesis. At the same time, changes in emphysema symptoms after banding or gastric bypass surgery in patients with marked obesity are also important from a clinical aspect.
In this context, we explored the long-term effects of gastrectomy on patients with spirometry-defined COPD and symptomatic patients who were at risk of COPD.

The preliminary data were presented at the American Thoracic Society conference in 2014, as an abstract.

\section{Materials and methods \\ Study population and study design}

We recruited patients with a definite COPD diagnosis (postbronchodilator forced expiratory volume in 1 second $\left[\mathrm{FEV}_{1}\right] /$ forced vital capacity $[\mathrm{FVC}]<70 \%$ ) and patients showing respiratory symptoms compatible with COPD but without airflow obstruction (postbronchodilator $\mathrm{FEV}_{1} / \mathrm{FVC}>70 \%$ ), defined as the at-risk group. All patients had undergone gastrectomy (group A) for gastric ulcer or early gastric cancer during the previous 10 years at various medical institutions, and subsequently, all presented with respiratory complaints from December 2003 to October 2013 at the Respiratory Care Clinic of Nippon Medical School in Tokyo, Japan, a secondary referral clinic primarily for patients with COPD. Patients who had undergone gastrectomy within 180 days before the start of the study were excluded. For each patient in group A, two patients matched by age ( \pm 5 years), sex, and $\mathrm{FEV}_{1}$ as a percentage of predicted $\left(\mathrm{FEV}_{1} \%\right.$ predicted) $( \pm 5 \%)$ were randomly selected for the control group (group B). No patients in groups A and B showed exacerbations; all had been in a stable condition for at least 3 months. ${ }^{1}$

This study was approved by the ethics committee of the Nippon Medical School (approval number: 18-11-31), and informed written consent of the participants was obtained before enrollment.

\section{Exclusion criteria}

Patients who had received any chemotherapy or radiation therapy for malignancy, including for gastric cancer, were excluded. In addition, patients were excluded if they presented with complications, such as bronchial asthma, bronchiectasis, diffuse panbronchiolitis, sinobronchial syndrome, pulmonary tuberculosis, nontuberculous mycobacteriosis, pneumoconiosis, lymphangioleiomyomatosis, congestive heart failure, interstitial pneumonitis, and lung cancer.

\section{Clinical, physiological, and imaging measurements}

All patients underwent routine blood chemistry and pulmonary function tests, arterial blood gas analysis, a 6-minute walk test (6MWT), high-resolution chest computed 
tomography (HRCT), nutritional assessments, assessment of the number of comorbidities, and a multidimensional assessment, as elucidated below.

\section{Pulmonary function tests}

Pulmonary function tests were performed by a well-trained technician according to the American Thoracic Society guidelines, ${ }^{13}$ using specialized equipment for lung function testing with computer processing (CHESTAC 55; CHEST M.I., Inc., Tokyo, Japan). The diagnosis and classification of COPD was based on the Global Initiative for Chronic Obstructive lung Disease (GOLD) criteria using postbronchodilator responses, ${ }^{1}$ and the reference values were based on the guidelines created by the Japan Thoracic Society. ${ }^{14}$

\section{High-resolution computed tomography}

We performed helical HRCT scans. The CT scans were obtained after deep inspiration. The percentage of low attenuation area (LAA\%) was calculated using previously reported methods. ${ }^{15}$ The cutoff level between the normal lung density and the LAA was defined as -960 Hounsfield units. The LAA\% for the upper, the middle, and the lower zones of the bilateral lung fields were calculated, and the overall mean values were used as representative values. ${ }^{15}$ The upper section was obtained at $1 \mathrm{~cm}$ above the superior margin of the aortic arch, the middle section at $1 \mathrm{~cm}$ below the carina, and the lower section at approximately $3 \mathrm{~cm}$ above the top of the diaphragm. We performed the helical HRCT scans at 1.25 mm collimation, 0.8-second scan time (rotation time), 120 $\mathrm{kV}$, and 100-600 mA, with a LightSpeed Pro16 CT Scanner (GE Healthcare Japan Co., Tokyo, Japan).

\section{Anthropometry and body composition}

We recorded patients' body height and weight. Body mass index (BMI) was calculated as:

$$
\mathrm{BMI}=\text { weight }(\mathrm{kg}) / \text { height }(\mathrm{m})^{2}
$$

Fat-free mass (FFM) and fat mass (FM) were measured by bioelectrical impedance analysis, at frequencies of 5, 50, 250, and $500 \mathrm{kHz}$ (InBody 3.2; Biospace Co. Ltd., Seoul, Republic of Korea). The FFM index (FFMI) was calculated as:

$$
\text { FFMI }=\text { FFM/height }(\mathrm{m})^{2}
$$

and the FM index (FMI) was calculated as:

$$
\mathrm{FMI}=\mathrm{FM} / \text { height }(\mathrm{m})^{2}
$$

At the time of each patient's first visit, we also obtained information regarding the use of prescribed medications.

\section{Comorbidity}

The number of comorbidities was expressed according to the Charlson Comorbidity Index. ${ }^{16}$

\section{Multidimensional assessment}

We assessed patients using the BMI, airflow obstruction, dyspnea, and exercise capacity (BODE) index, as reported previously. ${ }^{17}$

\section{Statistical analysis}

Discrete variables were expressed as counts (percentages) and continuous variables as mean \pm standard deviation (SD). The comparability of the groups was analyzed by the $\chi^{2}$ test, the Fisher exact test, the Student's $t$-test, and the Mann-Whitney $U$-test, as appropriate. The Kolmogorov-Smirnov test was applied to assess normal distribution. We investigated the predictors of exercise capacity using linear and logistic regression models. The data were analyzed using the PASW Statistics 18 for Windows software package (IBM Japan, Ltd). All $P$-values were two-sided; a $P$-value of $<0.05$ was considered statistically significant.

\section{Results}

Demographic and clinical characteristics of patients in both groups A and B are shown in Table 1. Group A consisted of 87 individuals, and group B consisted of 174 individuals. The mean ages of the patients in groups A and B were $71.4 \pm 7.7$ and $71.3 \pm 7.6$ years, respectively, and both groups showed a male predominance (252:9 [male to female]). In group A, the mean time that had elapsed postgastrectomy was $18.3 \pm 15.4$ years; the gastrectomies had been performed for mitigation of peptic ulcer $(n=28)$, malignancy $(n=58)$, or for unclarified reasons $(n=1)$. The patients had undergone partial $(n=66)$ or total $(n=21)$ gastrectomy. There were no significant differences in pharmacological interventions between groups A and B. The data of the pulmonary function tests from both Groups A and B gave mean of $\mathrm{FEV}_{1}$ and $\mathrm{FEV}_{1} \%$ predicted values of $2.07 \pm 0.76 \mathrm{~L}$ and $74.6 \pm 24.5 \%$, respectively. Based on the diagnostic criteria for COPD, 47 patients were diagnosed with COPD and 40 as being at risk of COPD in group A. In group B, 92 patients were diagnosed with COPD and 82 as at risk of COPD. There was no significant difference between the two groups in this respect $(P=0.86)$. Stages I, II, III, and IV of COPD (as per the GOLD classifications) were observed in ten, 21,14 , and two patients, 
Table I Demographic and clinical characteristics of the patients

\begin{tabular}{|c|c|c|c|}
\hline & Group A & Group B & $P$-value \\
\hline Patients, $\mathrm{n}$ & 87 & 174 & \\
\hline Age, years & $71.4 \pm 7.7$ & $71.3 \pm 7.6$ & 0.96 \\
\hline Sex male/female, $\mathrm{n}$ & $84 / 3$ & $168 / 6$ & 1.00 \\
\hline $\mathrm{BMI}, \mathrm{kg} \cdot \mathrm{m}^{-2}$ & $19.5 \pm 2.9$ & $22.6 \pm 3.1$ & 0.00 \\
\hline Smoking history (pack-years) & $63.8 \pm 39.9$ & $70.2 \pm 45.4$ & 0.35 \\
\hline Smoking status (current/ex/never) & $14 / 65 / 2^{\mathrm{a}}$ & $19 / 143 / 4^{b}$ & 0.45 \\
\hline Charlson Comorbidity Index & $1.6 \pm 1.4$ & $1.5 \pm 0.9$ & 0.76 \\
\hline \multicolumn{4}{|l|}{ Therapy } \\
\hline LAMA (use/no use) & $53 / 34$ & $|03 / 7|$ & 0.79 \\
\hline LABA (use/no use) & $61 / 26$ & $116 / 58$ & 0.57 \\
\hline ICS (use/no use) & $56 / 31$ & $98 / 76$ & 0.21 \\
\hline Theophylline (use/no use) & $9 / 78$ & $20 / 154$ & 0.78 \\
\hline Oral corticosteroid (use/no use) & $0 / 87$ & $2 / 172$ & 0.32 \\
\hline \multicolumn{4}{|l|}{ Pulmonary function tests } \\
\hline$\% \mathrm{VC}, \%$ & $90.5 \pm 20.2$ & $93.7 \pm 18.5$ & 0.31 \\
\hline $\mathrm{FEV}_{1} / \mathrm{FVC}, \%$ & $66.1 \pm 17.7$ & $64.2 \pm 16.8$ & 0.68 \\
\hline FEV $\%$ pred, $\%$ & $74.6 \pm 24.8$ & $74.6 \pm 24.4$ & 1.00 \\
\hline TLC, L & $5.7 \pm 1.2$ & $5.6 \pm 1.1$ & 0.38 \\
\hline$\% R V / T L C, \%$ & $115.6 \pm 23.7$ & $106.6 \pm 24.0$ & 0.01 \\
\hline$\% D L C O / V A, \%$ & $60.0 \pm 23.8$ & $65.6 \pm 24.4$ & 0.12 \\
\hline COPD/at risk of COPD* & $47 / 40$ & $92 / 82$ & 0.86 \\
\hline GOLD stage (I/II/III//IV) & $10 / 21 / 14 / 2^{c}$ & $17 / 43 / 28 / 4^{d}$ & 0.98 \\
\hline \multicolumn{4}{|l|}{ Blood gas analysis } \\
\hline $\mathrm{PaO}_{2}, \mathrm{mmHg}$ & $88.9 \pm 11.0$ & $84.0 \pm 10.0$ & 0.00 \\
\hline $\mathrm{PaCO}_{2}, \mathrm{mmHg}$ & $39.1 \pm 4.2$ & $39.5 \pm 4.1$ & 0.48 \\
\hline $\mathrm{A}-\mathrm{aDO}, \mathrm{mmHg}$ & $12.5 \pm 13.3$ & $16.3 \pm 10.5$ & 0.00 \\
\hline 6MWD, $\mathrm{m}$ & $453 \pm 105$ & $48 I \pm 98$ & 0.02 \\
\hline Strength of grip, kg & $29.7 \pm 7.6$ & $31.3 \pm 14.0$ & 0.10 \\
\hline Borg scale & $3.0 \pm 2.1$ & $3.1 \pm 2.0$ & 0.51 \\
\hline Leg fatigue & $2.2 \pm 1.8$ & $2.0 \pm 1.8$ & 0.37 \\
\hline OCD & $80.4 \pm 20.0$ & $80.7 \pm 20.8$ & 0.84 \\
\hline MMRC & $1.1 \pm 1.2$ & $1.0 \pm 0.9$ & 0.82 \\
\hline BODE index & $1.9 \pm 2.2$ & $1.2 \pm 1.8$ & 0.00 \\
\hline LAA\%, \% & $25.3 \pm 14.0$ & $24.4 \pm 14.9$ & 0.38 \\
\hline $\mathrm{FMI}, \mathrm{kg} \cdot \mathrm{m}^{-2}$ & $3.84 \pm 1.74$ & $5.67 \pm 1.86$ & 0.00 \\
\hline $\mathrm{FFMI}, \mathrm{kg} \cdot \mathrm{m}^{-2}$ & $16.03 \pm 1.72$ & $17.26 \pm 1.77$ & 0.00 \\
\hline $\mathrm{Hb}, \mathrm{g} \cdot \mathrm{dL}^{-1}$ & $13.0 \pm 1.6$ & $\mid 4.3 \pm 1.3$ & 0.00 \\
\hline Alb, g. $\mathrm{dL}^{-1}$ & $4 . I \pm 0.3$ & $4.3 \pm 0.3$ & 0.00 \\
\hline
\end{tabular}

Notes: Data are presented as mean \pm SD, unless otherwise stated. Stage I is defined as $\mathrm{FEV}, \%$ predicted $\geq 80 \%$; stage II is defined as $50 \% \leq \mathrm{FEV}, \%$ predicted $<80 \%$; stage III is defined as $30 \% \leq \mathrm{FEV} \%$ predicted $<50 \%$; and stage IV is defined as $\mathrm{FEV} \%$ predicted $<30 \%$ *At risk of COPD is defined as patients who showed symptoms compatible with COPD but who were not diagnosed with COPD. ${ }^{a} n=81 .{ }^{b} n=166$. ${ }^{\mathrm{c}} \mathrm{n}=47 .{ }^{\mathrm{d}} \mathrm{n}=92$.

Abbreviations: \%DLCO/VA, diffusing capacity divided by the alveolar volume as percentage of predicted; \%RV/TLC, residual volume to total lung capacity as percentage of predicted; \%VC, vital capacity as percentage of predicted; 6MWD, 6-minute walk distance; $\mathrm{A}-\mathrm{aDO}$, alveolar-arterial oxygen difference; $\mathrm{Alb}$, albumin; BMI, body mass index; BODE, body mass index, airway obstruction, dyspnea, and exercise capacity index; $\mathrm{FEV}$ \% predicted, forced expiratory volume in I second as percentage of predicted; $F E V / F V C$, forced expiratory volume in I second to forced vital capacity; FFMI, fat-free mass index; FMI, fat mass index; GOLD, Global initiative for vhronic Obstructive Lung Disease; Hb, Hemoglobin; ICS, inhaled corticosteroid; LAA\%, percentage of low attenuation area; LABA, long-acting beta 2 -agonist; LAMA, long-acting muscarinic antagonist; MMRC, modified Medical Research Council; OCD, oxygen cost diagram; $\mathrm{PaCO}_{2}$, partial pressure of carbon dioxide in arterial blood; $\mathrm{PaO}_{2}$, partial pressure of oxygen in arterial blood; SD, standard deviation;TLC, total lung capacity. respectively, in group A, and in 17,43, 28, and four patients, respectively, in group B. There was also no significant difference between the two groups in this respect $(P=0.98)$. Among the various parameters of the pulmonary function tests, the residual volume (RV) to total lung capacity (TLC) as percentage of predicted (\%RV/TLC) of group A was greater than that of group $\mathrm{B}(P=0.01)$. Since the difference in air trapping (as reflected by difference in RV/TLC) between the cases and the controls was $3.4 \%$ (45.5 $\pm 9.5 \%$ in group $A$ and $42.1 \pm 9.8 \%$ in group $\mathrm{B}[P=0.01])$ and the minimal important difference in RV/TLC was reported to range from 2.8 to $4.0 \%,{ }^{18}$ this difference in air trapping could have induced the symptomatic differences between these two groups. The BMI and the FFMI in group A were significantly lower than those in group $\mathrm{B}(P=0.00)$. Concentrations of both serum hemoglobin and albumin were significantly lower in group A than in group $\mathrm{B}(P=0.00$ for both) (Table 1$)$. The distance obtained in the 6MWT was significantly less for group A $(453 \pm 105 \mathrm{~m})$ than for group B $(481 \pm 98 \mathrm{~m})(P=0.02)$. The BODE index in group A was significantly higher than that in group $\mathrm{B}(P=0.00)$.

A comparative analysis of patients who underwent partial gastrectomy and those who underwent total gastrectomy in group $\mathrm{A}$ is shown in Table 2. The BMI $(P=0.016)$, FFMI $(P=0.035)$, FMI $(P=0.022)$, and hemoglobin levels $(P=0.003)$ were significantly lower in the patients who underwent total gastrectomy compared with those who underwent partial gastrectomy.

\section{Univariate and multivariate association with the 6MWT}

We performed univariate analyses using the 6MWT distance values for groups A and B (Table 3).

Subsequently, we performed multivariate linear regression analyses using various clinical and demographic parameters, and observed significant differences between groups A and B (Table 4). In group A, advanced age, increased $\% \mathrm{RV} / \mathrm{TLC}$, and decreased diffusing capacity for carbon monoxide (DLCO) divided by the alveolar volume (VA) as percentage of predicted (\%DLCO/VA) were independent and significant predictors of reduced distances in the 6MWT; while in group B, advanced age, decreased body height, decreased vital capacity (VC) as percentage of predicted $(\% \mathrm{VC})$, and decreased $\% \mathrm{DLCO} / \mathrm{VA}$ were independent predictors of reduced distances in the 6MWT. Comparisons between the two groups revealed \%RV/TLC as a specific indicator for determining the distances covered in the 6MWT in group A (Table 4). 
Table 2 Comparison of patients who underwent partial gastrectomy with those who underwent total gastrectomy in group $A$

\begin{tabular}{|c|c|c|c|}
\hline & $\begin{array}{l}\text { Partial } \\
\text { gastrectomy }\end{array}$ & $\begin{array}{l}\text { Total } \\
\text { gastrectomy }\end{array}$ & $P$-value \\
\hline Patients, $\mathrm{n}$ & 66 & 21 & \\
\hline Age, years & $70.8 \pm 7.9$ & $72.9 \pm 6.6$ & 0.28 \\
\hline $\mathrm{BMI}, \mathrm{kg} \cdot \mathrm{m}^{-2}$ & $19.9 \pm 3.0$ & $18.3 \pm 2.6$ & 0.02 \\
\hline$\%$ VC, \% & $90.9 \pm 18.6$ & $89.2 \pm 24.9$ & 0.79 \\
\hline $\mathrm{FEV}_{1}, \mathrm{~L} \cdot \mathrm{s}^{-1}$ & $2.05 \pm 0.74$ & $2.04 \pm 0.84$ & 0.90 \\
\hline $\mathrm{FEV}_{1} / \mathrm{FVC}, \%$ & $65.0 \pm 16.3$ & $69.5 \pm 21.3$ & 0.26 \\
\hline FEV $\%$ pred, \% & $73.2 \pm 22.9$ & $79.2 \pm 30.1$ & 0.28 \\
\hline TLC, L & $5.75 \pm 1.15$ & $5.7 I \pm I .54$ & 0.97 \\
\hline \%RV/TLC, \% & $114.3 \pm 23.0$ & $119.7 \pm 25.8$ & 0.52 \\
\hline$\% D L C O / V A, \%$ & $61.5 \pm 23.7$ & $55.3 \pm 24.3$ & 0.40 \\
\hline 6MWD, m & $453 \pm 113$ & $45 I \pm 7 \mid$ & 0.84 \\
\hline Strength of grip, kg & $30.3 \pm 7.8$ & $27.7 \pm 6.5$ & 0.32 \\
\hline MMRC & $1.0 \pm 1.1$ & $1.4 \pm 1.5$ & 0.40 \\
\hline BODE index & $1.9 \pm 2.1$ & $2.0 \pm 2.3$ & 0.95 \\
\hline LAA\%, \% & $26.0 \pm 14.1$ & $23.0 \pm 13.6$ & 0.40 \\
\hline $\mathrm{FMI}, \mathrm{kg} \cdot \mathrm{m}^{-2}$ & $4.08 \pm 1.76$ & $3.05 \pm 1.42$ & 0.02 \\
\hline $\mathrm{FFMI}, \mathrm{kg} \cdot \mathrm{m}^{-2}$ & $16.26 \pm 1.67$ & $15.26 \pm 1.70$ & 0.04 \\
\hline Alb, $g \cdot \mathrm{dL}^{-1}$ & $4.1 \pm 0.3$ & $4.1 \pm 0.4$ & 0.48 \\
\hline $\mathrm{Hb}, \mathrm{g} \cdot \mathrm{dL}^{-1}$ & $13.3 \pm 1.4$ & $12.0 \pm 1.7$ & 0.00 \\
\hline
\end{tabular}

Note: Data are presented as mean $\pm S D$, unless otherwise stated.

Abbreviations: \%DLCO/VA, diffusing capacity divided by the alveolar volume as percentage of predicted; \%RV/TLC, residual volume to total lung capacity as percentage of predicted; \%VC, vital capacity as percentage of predicted; 6MWD, 6-minute walk distance; Alb, albumin; BMI, body mass index; BODE, body mass index, airway obstruction, dyspnea, and exercise capacity index; $F E V_{1}$, forced expiratory volume in I second; FEV \% pred, forced expiratory volume in I second as percentage of predicted; $F E V_{1} / F V C$, forced expiratory volume in I second to forced vital capacity as percent of predicted; FFMI, fat-free mass index; FMI, fat mass index $\mathrm{Hb}$, Hemoglobin; LAA\%, percentage of low attenuation area; MMRC, Modified Medical Research Council; SD, standard deviation; TLC, total lung capacity.

\section{Discussion}

In this study, we observed several changes in patients with COPD who underwent gastrectomy. These patients demonstrated significant nutritional insufficiencies, significantly reduced exercise capacities, and shorter distances in the 6MWT compared with the patients who had not undergone gastrectomy. Univariate analysis revealed that age was an independent factor in determining the distances covered in the 6MWT. Multivariate linear regression analysis and comparisons between the two groups showed that increased $\% \mathrm{RV} / \mathrm{TLC}$ alone was an independent and significant predictor of reduced distances in the 6MWT. These data support the hypothesis that postgastrectomy, patients may experience reduced exercise capacity because of nutritional insufficiency. Moreover, these contributing physiological factors may indicate that hyperinflation is connected to the nutritional disorders resulting from gastrectomy.

Postgastrectomy syndrome, which frequently occurs after total or partial gastrectomy, is a lifelong source of problems
Table 3 Correlation between the 6-minute walk distance values and clinical and demographic parameters

\begin{tabular}{|c|c|c|c|c|}
\hline \multirow[t]{2}{*}{ Parameter } & \multicolumn{2}{|l|}{ Group A } & \multicolumn{2}{|l|}{ Group B } \\
\hline & $\begin{array}{l}\text { Correlation } \\
\text { coefficient }\end{array}$ & $P$-value & $\begin{array}{l}\text { Correlation } \\
\text { coefficient }\end{array}$ & $P$-value \\
\hline Age & -0.563 & 0.00 & -0.453 & 0.00 \\
\hline Height & 0.422 & 0.00 & $0.28 \mathrm{I}$ & 0.00 \\
\hline BMI & 0.179 & 0.11 & 0.254 & 0.00 \\
\hline $\mathrm{CCl}$ & -0.254 & 0.02 & -0.165 & 0.03 \\
\hline$\% \mathrm{VC}$ & 0.352 & 0.00 & 0.413 & 0.00 \\
\hline FEV $\%$ pred & 0.399 & 0.00 & 0.449 & 0.00 \\
\hline$\% \mathrm{RV} / \mathrm{TLC}$ & -0.282 & 0.01 & -0.329 & 0.00 \\
\hline$\% \mathrm{DLCO} / \mathrm{VA}$ & 0.424 & 0.00 & 0.486 & 0.00 \\
\hline $\mathrm{A}-\mathrm{aDO}{ }_{2}$ & 0.412 & 0.00 & -0.266 & 0.00 \\
\hline Strength of grip & 0.573 & 0.00 & 0.399 & 0.00 \\
\hline MMRC & -0.633 & 0.00 & -0.545 & 0.00 \\
\hline LAA\% & -0.229 & 0.05 & -0.328 & 0.00 \\
\hline FMI & -0.100 & 0.39 & 0.021 & 0.80 \\
\hline FFMI & 0.449 & 0.00 & 0.405 & 0.00 \\
\hline $\mathrm{Hb}$ & 0.302 & 0.01 & 0.148 & 0.06 \\
\hline Alb & 0.288 & 0.01 & 0.309 & 0.00 \\
\hline
\end{tabular}

Abbreviations: \%DLCO/VA, diffusing capacity divided by the alveolar volume as percentage of predicted; \%RV/TLC, residual volume to total lung capacity as percentage of predicted; \%VC, vital capacity as percentage of predicted; A-aDO2, alveolar-arterial oxygen difference; Alb, albumin; BMI, body mass index; $\mathrm{CCl}$, Charlson Comorbidity Index; FEV,\% pred, forced expiratory volume in I second as percentage of predicted; FFMI, fat-free mass index; FMI, fat mass index; $\mathrm{Hb}$, Hemoglobin; LAA\%, percentage of low attenuation area; MMRC, Modified Medical Research Council.

for patients. The difficulties associated with this syndrome include postprandial epigastric fullness, dumping syndrome, cholecystic dysfunction, malnutrition, and regurgitant gastroesophagitis. ${ }^{19}$ Segmental resection of the stomach was first described at the end of the 19th century by Mikulicz, who devised the procedure to preserve the pylorus when performing

Table 4 Multiple regression analyses for the 6-minute walk distance values in groups $A$ and $B$

\begin{tabular}{lllll}
\hline Parameters & B* & B** & $\mathbf{9 5 \%} \mathbf{C l}$ & P-value \\
\hline $\begin{array}{l}\text { Group A } \\
\text { Age, years }\end{array}$ & -8.346 & -0.569 & -10.74 I to -5.95 I & 0.000 \\
$\begin{array}{l}\text { \%RV/TLC, \% } \\
\text { \%DLCO/VA, \% }\end{array}$ & -1.740 & -0.36 I & -2.577 to -0.903 & 0.000 \\
& 1.048 & 0.223 & 0.233 to 1.874 & 0.014 \\
Group B & & & & $R^{2}=0.563$ \\
\%DLCO/VA, \% & 1.683 & 0.423 & 1.176 to 2.190 & 0.000 \\
\%VC, \% & 2.029 & 0.380 & 1.359 to 2.699 & 0.000 \\
Age, years & -2.335 & -0.179 & -4.088 to -0.582 & 0.009 \\
Height, centimeters & 2.123 & 0.132 & 0.029 to 4.217 & 0.047 \\
& & & & $R^{2}=0.463$ \\
\hline
\end{tabular}

Notes: *Unstandardized coefficient. **Standardized coefficient.

Abbreviations: \%DLCO/VA, diffusing capacity divided by the alveolar volume as percentage of predicted; \%RV/TLC, residual volume to total lung capacity as percentage of predicted; \%VC, vital capacity as percentage of predicted; $\mathrm{Cl}$, confidence interval. 
gastric ulcer surgery. ${ }^{20}$ This technique was eventually abandoned because it caused delayed gastric emptying. In 1967, Maki et al developed an improved concept of segmental gastrectomy: pylorus-preserving gastrectomy, ${ }^{19}$ but dramatic decreases in the occurrence of gastric ulcers limited the opportunity to perform the operation. However, pylorus-preserving gastrectomy has emerged as a surgical technique for gastric cancer, the incidence of which has increased remarkably over the last two decades. ${ }^{19}$ In our study, approximately two-thirds of all gastrectomized patients underwent this surgical procedure for gastric cancer. We have shown that patients who underwent a total gastrectomy showed greater nutritional insufficiency than those who underwent partial gastrectomy. However, we did not investigate whether the use of pylorus-preserving gastrectomy affects nutritional insufficiency several years after surgery as there was insufficient information available for most of the patients.

The present study was performed using a cross-sectional design, and data were not available to indicate whether defined COPD was present at the time of each gastrectomy. Each patient had a complex background, defined by different severities of COPD, age, and sex. Therefore, we compared the patients with COPD and a history of gastrectomy to those without gastrectomy, using a case-control model: the patients were matched by age ( \pm 5 years), sex, and $\mathrm{FEV}_{1} \%$ predicted $( \pm 5 \%)$. The two groups differed with respect to BMI but not with respect to smoking history (expressed as pack-years) and medications prescribed for management of COPD.

It has been established that nutritional status is one of the most important clinical determinants of postgastrectomy outcomes. Weight loss is a common problem in patients who have undergone gastrectomy, mainly due to impaired food intake and malabsorption. ${ }^{21}$ The pathophysiology of patients with COPD includes narrowing of the peripheral airways, decreased parenchymal tethering of the airways, loss of alveolar surface area, pulmonary hyperinflation, and air trapping. ${ }^{22}$ Continued malnutrition was associated with and could lead to emphysema, which was observed in $13.5 \%$ of people in the Warsaw Ghetto during World War $\mathrm{II}^{23}$ and in patients with anorexia nervosa. ${ }^{24}$ However, our data did not support a direct relationship between the severity of emphysema (assessed on chest HRCT) and nutritional insufficiency. This is likely due to the relatively milder nutritional insufficiency in postgastrectomy patients as compared with that suffered by people in the Warsaw Ghetto. ${ }^{23}$ However, the gastrectomy group did show reduced exercise capacity and hyperinflation.
Gastrectomy was associated with anemia in our study, which could lead to pulmonary hypertension $(\mathrm{PH})$ and poor outcomes in subjects with COPD. Anemia is common in patients with chronic respiratory failure, including COPD, often because of disturbed iron homeostasis. ${ }^{25}$ Recent studies have reported that iron deficiency in patients with, not only idiopathic pulmonary arterial hypertension ${ }^{26}$ but also, various other forms of $\mathrm{PH}$ is associated with worsened clinical outcome, ${ }^{27}$ and iron is also thought to play a key role in many cellular processes, including responses to hypoxia and oxidative stress, cellular proliferation, and cell metabolism. The potential importance of iron supplementation in patients with PH has also been examined. ${ }^{27}$ It has been reported that hypoxic PH may be attenuated and quality of life and exercise capacity could be improved through the use of iron supplementation..$^{28,29}$ Thus, disturbance of iron homeostasis could lead to anemia and PH in COPD, and these comorbidities might possibly be cured by iron supplementation. In fact, it has also been reported that iron deficiency is common in patients with COPD and that correction of this iron deficiency with intravenous iron supplementation can improve their anemia and dyspnea. ${ }^{30}$

Hyperinflation in COPD is characterized by an increase in absolute lung volumes. This is thought to be partly due to inadequate emptying of the lungs, which can be caused by an increase in airway resistance and respiratory system compliance, or a combination of the two. ${ }^{31}$ The patients who underwent gastrectomy did not have obvious airflow obstruction but did have hyperinflation of the lungs. This suggests that gastrectomy does not increase lung inflammation or tissue destruction; however, malnutrition does induce decreases in lung elastin and collagen levels. ${ }^{32}$ Recently, it was found that proteoglycan plays an important role in lung health as well. ${ }^{33}$ Lung elasticity and alveolar stability are observed at low to medium lung volumes. ${ }^{33}$ Changes in these connective tissues can cause decreased lung elasticity, which results in lung hyperinflation.

Determinants of shorter distances in 6MWT are complex and depend on both physical factors (pulmonary and nonpulmonary) and psychological factors, as reported in the results of a large multinational cohort of well-characterized patients with clinically stable, moderate to very severe COPD ${ }^{34}$ In the present study, we did not quantify the effects of psychological factors on our results, although they may have some effect on postgastrectomy patients. ${ }^{35}$ In a previous study, emphysema and gas trapping, as measured by CT scan, were not found to be predictive of 6MWT distances. ${ }^{36}$ In our study, we found that hyperinflation, expressed as $\% \mathrm{RV} / \mathrm{TLC}$, was 
predictive of the distances covered in the 6MWT. Since every $1 \%$ increase in $\% \mathrm{RV} / \mathrm{TLC}$ resulted in a decrease of $1.740 \mathrm{~m}$ in the 6-minute walk distances in group A (Table 4), a 15\% increase in $\% \mathrm{RV} / \mathrm{TLC}$ was associated with a reduction in the 6-minute walk distances of $26 \mathrm{~m}$, which has been reported as the minimal important difference. ${ }^{37}$

\section{Strengths and limitations}

To adequately appreciate our results, the strengths of this study must be acknowledged. The current study was conducted using a sufficient number of patients with COPD who had undergone gastrectomy. Patients who received gastrectomy for gastric cancer, who may have demonstrated the effects of recurrence or chemotherapy, were not included in the present study; therefore, the study design was appropriate to study the effects of gastrectomy alone. However, our study also had certain limitations. First, a heterogeneous group of patients with COPD or at risk of COPD was enrolled in the study. This might have been a source of potential confounding factors, as patients with spirometry-defined COPD and patients at risk of COPD have distinct phenotypes, especially when the effects of obesity or weight gain are involved; ${ }^{38}$ of note, the Charlson Comorbidity Index did not differ between the two groups. Second, this study included only Japanese patients, in whom the prevalence of emphysema type and weight loss is different from that seen in Caucasians. ${ }^{39}$ In addition, we had very few women in our study population, possibly because the morbidity of COPD is three times higher in males than in females ${ }^{40}$ and because in Japan, the morbidity of gastric cancer and ulcer is also higher in males than in females. ${ }^{41,42}$ We believe these factors, namely the ethnic and sex differences, need to be assessed in follow-up studies. Third, we only estimated hyperinflation as \%RV/TLC; we did not measure dynamic hyperinflation in this study. Further, we recommend evaluating annual changes in the results of both the 6MWT and the lung function tests after gastrectomy, as well as studying different populations, as future research directions. The study could also be refined by examining the differences in the histories of patients with marked obesity who underwent gastrectomy, gastric bypass, or banding. Finally, our study also could have a healthy survivor bias. Since we have seen only long-term survivors who underwent gastrectomy, this study could be limited in its ability to analyze the overall effects of gastrectomy on pulmonary outcomes. This should be elucidated in the future, with a prospective study that could also include subjects without respiratory complaints at study recruitment.

\section{Conclusion}

We concluded that nutritional insufficiency in patients with COPD (or at risk of COPD) who previously underwent gastrectomy might lead to hyperinflation and consequently, decreased exercise capacity.

\section{Acknowledgments}

The authors thank all the nurses and clinical technologists of the Respiratory Care Clinic, Nippon Medical School, for collecting the clinical and physiological data.

\section{Disclosure}

The authors have no conflicts of interest in connection with this work.

\section{References}

1. Global Initiative for Chronic Obstructive Lung Disease (GOLD) 2015. Global strategy for the diagnosis, management, and prevention of chronic obstructive pulmonary disease. Available from: www.goldcopd. com. Accessed April 22, 2015.

2. Rutten EP, Lenaerts K, Buurman WA, et al. Disturbed intestinal integrity in patients with COPD: effects of activities of daily living. Chest. 2014;145:245-252.

3. Kojima M, Hosoda H, Date Y, et al. Ghrelin is a growth-hormone-releasing acylated peptide from stomach. Nature. 1999;402: 656-660.

4. Nagaya N, Itoh T, Murakami S, et al. Treatment of cachexia with ghrelin in patients with COPD. Chest. 2005;128:1187-1193.

5. Cummings DE, Weigle DS, Frayo RS, et al. Plasma ghrelin levels after diet-induced weight loss or gastric bypass surgery. $N$ Engl J Med. 2002;346:1623-1630.

6. Hanusch-Enserer U, Brabant G, Roden M. Ghrelin concentrations in morbidly obese patients after adjustable gastric banding. $N$ Engl J Med. 2003;348:2159-2160.

7. Patrikakos P, Toutouzas KG, Gazouli M, et al. Long-term plasma ghrelin and leptin modulation after sleeve gastrectomy in Wistar rats in comparison with gastric tissue ghrelin expression. Obes Surg. 2011; 21:1432-1437.

8. Karamanakos SN, Vagenas K, Kalfarentzos F, et al. Weight loss, appetite suppression, and changes in fasting and postprandial ghrelin and peptide-YY levels after Roux-en-Y gastric bypass and sleeve gastrectomy: a prospective, double blind study. Ann Surg. 2008;247:401-407.

9. Batterham RL, Cowley MA, Small CJ, et al. Gut hormone PYY3-36 physiologically inhibits food intake. Nature. 2002;418:650-654.

10. Ryan KK, Tremaroli V, Clemmensen C, et al. FXR is a molecular target for the effects of vertical sleeve gastrectomy. Nature. 2014;509: $183-188$.

11. Thurlbeck WM, Wright JL. Diseases in other organs. In: Thurlbeck WM, Wright JL, editors. Thurlbeck's Chronic Airflow Obstruction, Second edition. Hamilton, Ontario: B.C. Decker Inc; 1999:311-323.

12. Gisbert JP, Pajares JM. Helicobactor pylori infection and perforated peptic ulcer prevalence of the infection and role of antimicrobial treatment. Helicobacter. 2003;8:159-167.

13. Standardization of spirometry, 1994 update: American Thoracic Society. Am J Respir Crit Care Med. 1995;152:1107-1136.

14. Japanese Respiratory Society. The predicted values of spirometry and arterial blood gas analysis in Japanese [in Japanese]. J Jpn Resp Soc. 2001;39:appendix.

15. Nakano Y, Muro S, Sakai H, et al. Computed tomographic measurements of airway dimensions and emphysema in smokers: correlation with lung function. Am J Respir Crit Care Med. 2000;162:1102-1108. 
16. Charlson M, Szatrowski TP, Peterson J, et al. Validation of a combined comorbidity index. J Clin Epidemiol. 1994;47:1245-1251.

17. Celli BR, Cote CG, Marin JM, et al. The body-mass index, airflow obstruction, dyspnea, and exercise capacity index in chronic obstructive pulmonary disease. $N$ Engl J Med. 2004;350:1005-1012.

18. Hartman JE, Ten Hacken NH, Klooster K, Boezen HM, de Greef MH, Slebos DJ. The minimal important difference for residual volume in patients with severe emphysema. Eur Respir J. 2012;40:1137-1141.

19. Fujimura T, Fushida S, Kayahara M, et al. Transectional gastrectomy: an old but renewed concept for early gastric cancer. Surg Today. 2010;40: 398-403.

20. Kielan W, Lazarkiewicz B, Grzebieniak Z, et al. Jan Mikulicz-Radecki: one of the creators of world surgery. Keio J Med. 2005;54:1-7.

21. Armbrecht U, Lundell L, Lindstedt G, et al. Causes of malabsorption after total gastrectomy with Roux-en-Y reconstruction. Acta Chir Scand. 1988;154:37-41.

22. McDonough JE, Yuan R, Suzuki M, et al. Small-airway obstruction and emphysema in chronic obstructive pulmonary disease. $N$ Engl J Med. 2011;365:1567-1575.

23. Fliederbaum J. Clinical aspects of hunger disease in adults. In: Winick $M$, ed. Hunger Disease: Studies by the Jewish Physicians in the Warsaw Ghetto. New York: John Wiley \& Sons; 1979:11-36.

24. Coxson HO, Chan IHT, Mayo JR, et al. Early emphysema in patients with anorexia nervosa. Am J Respir Crit Care Med. 2004;170:748-752.

25. Schneckenpointner R, Jorres RA, Meidenbauer N, Kollert F, Pfeifer M, Budweiser S. The clinical significance of anaemia and disturbed iron homeostasis in chronic respiratory failure. Int J Clin Pract. 2014; 68: $130-138$.

26. Rhodes CJ, Howard LS, Busbridge M, et al. Iron deficiency and raised hepcidin in idiopathic pulmonary arterial hypertension: clinical prevalence, outcomes, and mechanistic insights. J Am Coll Cardiol. 2011;58:300-309.

27. Robinson JC, Graham BB, Rouault TC, Tuder RM. The crossroads of iron with hypoxia and cellular metabolism. Implications in the pathobiology of pulmonary hypertension. Am J Respir Cell Mol Biol. 2014;51:721-729.

28. Smith TG, Talbot NP, Privat C, et al. Effects of iron supplementation and depletion on hypoxic pulmonary hypertension: two randomized controlled trials. JAMA. 2009;302:1444-1450.

29. Viethen T, Gerhardt F, Dumitrescu D, et al. Ferric carboxymaltose improves exercise capacity and quality of life in patients with pulmonary arterial hypertension and iron deficiency: a pilot study. Int J Cardiol. 2014;175:233-239.
30. Silverberg DS, Mor R, Weu MT, Schwartz D, Schwartz IF, Chernin G. Anemia and iron deficiency in COPD patients: prevalence and the effects of correction of the anemia with erythropoiesis stimulating agents and intravenous iron. BMC Pulm Med. 2014;14:24.

31. Bancalari E, Clausen J. Pathophysiology of changes in absolute lung volumes. Eur Respir J. 1998;12:248-258.

32. Kalenga M, Eeckhout Y. Effect of protein deprivation from the neonatal period on lung collagen and elastin in the rat. Pediatr Res. 1989;26:125-127.

33. Cavalcante FS, Ito S, Brewer K, et al. Mechanical interactions between collagen and proteoglycans: implications for the stability of lung tissue. J Appl Physiol. 2005;98:672-679.

34. Spruit MA, Watkins ML, Edwards LD, et al. Evaluation of COPD longitudinally to identify predictive surrogate endpoints (ECLIPSE) study investigators: determinants of poor 6-min walking distance in patients with COPD: the ECLIPSE cohort. Respir Med. 2010;104:849-857.

35. Svedlund J, Sullivan M, Liedman B, et al. Long term consequences of gastrectomy for patient's quality of life: the impact of reconstructive techniques. Am J Gastroenterol. 1999;94:438-445.

36. Rambod M, Porszasz J, Make BJ, et al. Six-minute walk distance predictors, including CT scan measures, in the COPDGene cohort. Chest. 2012;141:867-875.

37. Puhan MA, Chandra D, Mosenifar Z, et al. The minimal important difference of exercise tests in severe COPD. Eur Respir J. 2011;37: 784-790.

38. Jordan JG Jr, Mann JR. Obesity and mortality in persons with obstructive lung disease using data from the NHANES III. South Med J. 2010;103: 323-330.

39. Makita H, Nasuhara Y, Nagai K. Characterisation of phenotypes based on severity of emphysema in chronic obstructive pulmonary disease. Thorax. 2007;62:932-937.

40. Fukuchi Y, Nishimura M, Ichinose M, et al. COPD in Japan: the Nippon COPD Epidemiology study. Respirology. 2004;9:458-465.

41. Maruyama K, Katai H. Surgical treatment of gastric cancer in Japan, trend from standardization to individualization. Chirurgia (Bucur). 2014;109:722-730

42. Sasaki I, Fukushima K, Naito H, Matsuno S, Shiratori T, Maki T. Long-term results of pylorus-preserving gastrectomy for gastric ulcer. Tohoku J Exp Med. 1992;168:539-548.
International Journal of COPD

\section{Publish your work in this journal}

The International Journal of COPD is an international, peer-reviewed journal of therapeutics and pharmacology focusing on concise rapid reporting of clinical studies and reviews in COPD. Special focus is given to the pathophysiological processes underlying the disease, intervention programs, patient focused education, and self management protocols.
Dovepress

This journal is indexed on PubMed Central, MedLine and CAS. The manuscript management system is completely online and includes a very quick and fair peer-review system, which is all easy to use. Visit http://www.dovepress.com/testimonials.php to read real quotes from published authors. 